\section{Normative Data}

Molly E. Zimmerman

Department of Psychology, Fordham University, Bronx, NY, USA

\section{Synonyms}

Norms

\section{Definition}

Normative data are broadly conceptualized as a collection of test scores derived from the administration of an assessment to a sample that is representative of the general population. To obtain stable estimates of population values, relatively large sample sizes must be employed.

\section{Current Knowledge}

A given individual's performance can be characterized through empirical comparison of his/her test score to normative data (Mitrushina et al. 2005). Since performance on neuropsychological tests has been shown to vary as a function of several demographic variables, normative data are typically stratified on specific categories, such as age-groups, gender, ethnicity, or race (Lezak et al. 2012). An important component of standard neuropsychological practice is the selection of normative data that are appropriate for the individual being assessed. Sample size and composition and the date of data collection are critical considerations when choosing normative data sets for both clinical and research use (Strauss et al. 2006). Neuropsychologists may find that it is useful to compare an individual's test score with that of several different normative data sets to most accurately characterize that individual's performance (Lezak et al. 2012).

\section{Cross-References}

Standard Scores

\section{References and Readings}

Lezak, M. D., Howieson, D. B., Bigler, E. D., \& Tranel, D. (2012). Neuropsychological assessment. Oxford: Oxford University Press.

Mitrushina, M., Boone, K. B., Razani, J., \& D’Elia, L. F. (2005). Handbook of normative data for neuropsychological assessment. Oxford: Oxford University Press.

Strauss, E., Sherman, E. M. S., \& Spreen, O. (2006). A compendium of neuropsychological tests: Administration, norms, and commentary. Oxford: Oxford University Press. 